\title{
CRESCIMENTO DE FRUTOS DA TANGERINEIRA 'PONCÃ' (Citrus reticulata Blanco) ${ }^{1}$
}

\author{
MARLON DUTRA DEGLI ESPOSTI ${ }^{2}$, DALMO LOPES DE SIQUEIRA ${ }^{3}$, PAULO ROBERTO CECON $^{4}$
}

RESUMO- Este trabalho foi realizado com o objetivo de avaliar o desenvolvimento de frutos da tangerineira Poncã, desde o pegamento até a colheita dos frutos, em Viçosa - Minas Gerais. O desenvolvimento do fruto seguiu uma curva do tipo sigmóide simples, sendo a fase I compreendida da antese até o $85^{\circ}$ dia após o pleno florescimento, com um período de transição na fase II, que foi até o $101^{\circ}$ dia após o pleno florescimento. A fase II teve início logo após a fase de transição, prolongando-se até o $251^{\circ}$ dia após o pleno florescimento. A fase III, de amadurecimento do fruto, iniciou-se no $251^{\circ}$ dia após o pleno florescimento e prolongou-se até a colheita dos frutos, a qual foi realizada no $276^{\circ}$ dia após o pleno florescimento.

Termos para indexação: florescimento, massa do fruto, diâmetro do fruto.

\section{FRUIT GOWTH OF 'PONKAN' MANDARIN}

ABSTRACT- The objective of this work was to evaluate the fruit development of Ponkan mandarin (Citrus reticulata Blanco). Fruit development followed a simple sigmoid curve, with phase I extending from anthesis to the $85^{\text {th }}$ day after full flowering, with a transition period to phase II that lasted up to the $101^{\text {st }}$ day after full flowering. Phase II began soon after the transition phase, extending up to the $251^{\text {st }}$ day after full flowering. Phase III, fruit ripening, began at the $251^{\text {st }}$ day after full flowering and it was prolonged until harvest, which was carried out at the $276^{\text {th }}$ day after full flowering.

Index terms: flowering, fruit mass, fruit diameter.

\section{INTRODUÇÃO}

Embora os citros estejam entre as espécies frutíferas mais pesquisadas no Brasil, as pesquisas enfatizam principalmente os aspectos relacionados aos tratos culturais e fitossanidade, havendo poucas pesquisas sobre o conhecimento da planta (botânica e fisiologia). Informações sobre o crescimento e o desenvolvimento dos frutos são importantes, pois esses processos influenciam na qualidade dos frutos e facilitam o planejamento da colheita. Particularmente para a tangerineira Poncã, que produz frutos de importância econômica para a citricultura nacional e mineira, não foram encontrados trabalhos a respeito do crescimento e desenvolvimento de seus frutos. A tangerina 'Poncã' é um fruto grande, com massa média oscilando entre 196,5 a 222,5 g (Pio et al., 2006), de forma achatada, com casca fina ou média, pouco aderente e vesículas de óleo salientes (Salibe, 1997). Sua polpa é de cor alaranjada e a textura é frouxa. O suco corresponde a $40 \%$ do peso do fruto, com os teores médios de Brix de 10,8\%, valores de acidez de $0,85 \%$ e ratio de 12,7 (Genú, 1985).

O desenvolvimento dos frutos das espécies do gênero Citrus segue uma curva sigmóide simples, que é caracterizada por três principais estádios, que se sobrepõem sucessivamente, sendo praticamente impossível delimitar o exato final de um e o início do subseqüente (Spiegel-Roy \& Goldschmidt, 1996). O primeiro é o da divisão celular (fase I), o segundo é o da expansão celular (fase II) e o terceiro é o do amadurecimento (fase III). A divisão celular parece ocorrer, em todos os tecidos dos frutos, somente até cinco a dez semanas após a floração, com exceção das camadas externas do flavedo e dos ápices das vesículas de suco. Essa fase caracteriza-se por um rápido crescimento, provocado pela alta taxa de divisão celular e conseqüente aumento do número de células de todos os seus tecidos em desenvolvimento, exceto o eixo central. Nessa fase, o aumento no tamanho do fruto é devido, principalmente, ao crescimento da casca, embora também já seja possível observar a expansão celular (Bain, 1958). A divisão celular dura cerca de um mês em laranjas (Bain, 1958), mas pode apresentar variações, dependendo da espécie e da variedade. Algumas variedades de tangerineira Satsuma (Citrus unshiu), por exemplo, têm período de divisão celular de 45 e 35 dias após a antese, respectivamente, nas variedades 'Clausellina' e 'Okitsu' (Mehouachi et al., 1995). Essas diferenças de tempo nas fases de crescimento dos frutos provavelmente se devem às características genéticas de cada espécie e cultivar, ao clima e solo da região, e aos tratos culturais aplicados. A fase II dura vários meses, prosseguindo até pouco antes da sua mudança de cor da casca dos frutos. Sua duração varia em função da variedade, sendo curta nas precoces (dois meses) e longa nas tardias (5 - 6 meses). Essa fase caracteriza-se pela expansão dos tecidos, acompanhada por aumento celular e formação de um mesocarpo esponjoso, com ausência de divisão celular em quase todos os tecidos, exceto do exocarpo. Nessa fase, o aumento do tamanho deve-se, principalmente, ao desenvolvimento dos lóculos, em cujo interior as vesículas

'(Trabalho 218-07). Recebido em: 24-09-2007. Aceito para publicação em: 15-02-2008.

${ }^{2}$ INCAPER, Avenida Cristiano Dias Lopes Filho, s/n, CEP: 29330-000 - Itapemirim-ES - E-mail: mesposti@incaper.es.gov.br

${ }^{3}$ Universidade Federal de Viçosa, Departamento de Fitotecnia - CEP 36570-000, Viçosa - MG - Email:siqueira@ufv.br

${ }^{4}$ Universidade Federal de Viçosa, Departamento de Informática - CEP 36570-000, Viçosa - MG - Email:cecon@dpi.ufv.br 
chegam a alcançar seu máximo comprimento e conteúdo de suco (Bain, 1958). A fase III caracteriza-se pela reduzida taxa de crescimento. Compreende todas as mudanças associadas ao amadurecimento. Nessa fase, a pigmentação da casca é conseqüência da degradação enzimática das clorofilas do flavedo e da síntese de carotenóides. Segundo Bain (1958), esses processos normalmente coincidem com o amadurecimento interno, embora estejam sujeitos a controles distintos. O conteúdo de sólidos solúveis, sobretudo açúcares, aumenta, enquanto o dos ácidos livres diminui.

O presente trabalho foi realizado com o objetivo de avaliar o desenvolvimento de frutos de tangerineira 'Poncã', desde o pegamento até a colheita dos frutos, em Viçosa - Minas Gerais.

\section{MATERIAL E MÉTODOS}

O trabalho foi realizado no pomar do Fundão, localizado no Setor de Fruticultura da Universidade Federal de Viçosa (UFV), em Viçosa-MG, o qual está situado a $20^{\circ} 45^{\prime}$ de latitude sul e $42^{\circ}$ $51^{\prime}$ de longitude oeste, apresentando uma altitude de $650 \mathrm{~m}$. O clima da região foi classificado, pelo sistema de Köeppen, como Cwa-mesotérmico úmido, com verões úmidos e invernos secos; a média anual das temperaturas máximas é de $26,1^{\circ} \mathrm{C}$, e das mínimas, $14,0^{\circ} \mathrm{C}$; a pluviosidade anual é de $1.340 \mathrm{~mm}$, e a umidade relativa média anual, de $80 \%$.

Foram utilizadas plantas de tangerineira 'Poncã' (Citrus reticulata Blanco) com cinco anos de idade, enxertadas sobre o limoeiro 'Cravo' (Citrus limonia Osbeck). Foi usado o espaçamento de $6,0 \mathrm{~m}$ entre linhas e 4,0 m entre plantas. As características químicas e físicas do solo da área experimental, na época das avaliações, podem ser vistas na Tabela 1. Em 2001, ano em que foi dado início a este trabalho, foram aplicadas todas as práticas culturais normais à cultura, à exceção da irrigação e da adubação foliar das plantas. O crescimento dos frutos foi avaliado medindo-se o diâmetro transversal de 20 frutos selecionados em uma única planta dentro da área experimental. Os diâmetros dos frutos foram determinados com paquímetro digital, a cada 15 dias, logo após o término da queda fisiológica (outubro). As massas fresca e seca dos 20 frutos selecionados foram estimadas indiretamente, usando equações de regressão, que foram determinadas para cada data de avaliação, colhendose amostras de 15 frutos, em outras plantas da área experimental, cujos diâmetros estavam compreendidos entre os diâmetros máximo e mínimo dos vinte frutos selecionados. Os 15 frutos foram avaliados individualmente, tomando-se o diâmetro equatorial, a massa fresca total e as massas fresca e seca da casca e da polpa. A massa dos 15 frutos relacionou-se com o seu diâmetro, enquanto as demais características se relacionaram com a massa total dos frutos. Assim, com base nas equações de regressão obtidas (Tabela 1) e no diâmetro dos 20 frutos selecionados, foi possível estimar sua massa. Da mesma forma, usando as equações que relacionaram a massa média dos 15 frutos com as massas fresca e seca da casca e polpa (Tabela 2), foi possível estimar as massas fresca e seca dos 20 frutos marcados na planta. Com os dados obtidos, foram determinadas as curvas de crescimento dos frutos e a taxa de crescimento relativo por meio da fórmula $T C R=\left(V_{1}-V_{0}\right) /\left(T_{1}-T_{0}\right)$, em que: $\mathrm{TCR}=$ taxa de crescimento relativo $; \mathrm{V}=$ valores das características avaliadas; $\mathrm{V}_{0}=$ valor inicial; $\mathrm{V}_{1}=$ valor final; $\mathrm{T}=$ época da avaliação (dias após o pleno florescimento); $\mathrm{T}_{0}=$ tempo inicial, $\mathrm{e}_{1}=$ tempo final.

\section{RESULTADOS E DISCUSSÃO}

O desenvolvimento dos frutos da 'Poncã' seguiu uma curva do tipo sigmóide simples, desde o pegamento até a colheita, sendo esse comportamento mais evidente para a massa do fruto (g) e massas fresca e seca da polpa (Figuras 1 e 2). As diferenças no padrão de crescimento dos frutos de várias espécies, quando são utilizadas diferentes unidades de medidas, foram relatadas por diversos autores. O uso do volume do fruto proporcionou uma curva do tipo sigmóide simples para o crescimento de pêssegos (Miller et al., 1998), enquanto, para o diâmetro e a massa fresca de frutos, foi obtida uma curva do tipo sigmóide dupla (Hayama et al., 2001), sendo esta última a mais indicada para expressar o crescimento dos frutos dessa espécie.

A avaliação do crescimento dos frutos iniciou-se no $85^{\circ}$ dia após o pleno florescimento, logo após o término da queda fisiológica; portanto, a fase I, que tem início na antese e prolongase até o final da queda fisiológica, não pôde ser determinada. Essa fase é caracterizada por um rápido crescimento do fruto, provocado pela alta taxa de divisão celular, sendo o tamanho do fruto dependente do crescimento da casca. Neste trabalho, observou-se que as massas fresca e seca da casca apresentaram valores superiores aos obtidos para as massas fresca e seca da polpa, até o 113 e $145^{\circ}$ dia após o pleno florescimento, respectivamente (Figura 2).

A partir do 113 e $145^{\circ}$ dias após o pleno florescimento, o desenvolvimento do fruto passou a ser dependente do crescimento da polpa, sendo esse comportamento observado até a colheita, o que ocorreu no $276^{\circ}$ dia após o pleno florescimento. Nesse período, o maior crescimento da polpa em relação à casca deve-se, principalmente, ao desenvolvimento dos lóculos, em cujo interior as vesículas de suco chegam a alcançar seu máximo comprimento e conteúdo de suco. Esse ciclo é conhecido como fase II, ou fase de expansão celular (Bain, 1958; Guardiola et al., 1993).

A taxa de crescimento relativo dos frutos da tangerineira 'Poncã' ilustra, de forma clara, o início da fase de expansão celular (fase II), na qual o desenvolvimento do fruto passa a ser dependente do crescimento da polpa, principalmente no período compreendido entre o $101^{\circ}$ e o $251^{\circ}$ dia após o pleno florescimento (Figura 3). Inicialmente, a taxa de crescimento relativo foi lenta, não se observando diferenças marcantes entre o crescimento da casca e da polpa até o $101^{\circ}$ dia após o pleno florescimento. A partir dessa data e até o $251^{\circ}$ dia após o pleno florescimento, a taxa de crescimento relativo da polpa passou a mostrar os maiores valores, seguindo-se o mesmo comportamento da taxa de crescimento relativo do fruto. A partir do $251^{\circ}$ dia, houve menor redução na taxa de crescimento relativo, em razão do aumento significativo na taxa de crescimento relativo da casca, observado claramente no período do $251^{\circ}$ ao $276^{\circ}$ dia após o pleno 
florescimento (Figura 3).

Esse comportamento de retomada do desenvolvimento da casca é comum nas espécies de tangerineiras, principalmente na variedade 'Poncã', em que, juntamente com a redução ou, mesmo, paralisação do crescimento da polpa, há o aparecimento de espaços vazios entre a casca e a polpa dos frutos. Fronfría et al. (1996) citam que o crescimento da casca de algumas variedades de tangerinas, como as Satsumas, nessa fase é importante. $\mathrm{O}$ aumento na taxa de crescimento relativo da casca a partir do $251^{\circ}$ dia após o pleno florescimento e a freqüente queda na taxa de crescimento relativo da polpa parecem indicar o final da fase de expansão celular (fase II), que, segundo Bain (1958), pode prolongar-se por vários meses, desde o final da queda fisiológica dos frutos até pouco antes da sua mudança de cor.

A partir dos resultados, é possível definir as diferentes fases de crescimento do fruto da tangerineira 'Poncã'. A fase I está compreendida entre a antese até o $85^{\circ}$ dia após o pleno florescimento, com um período de transição para a fase II, que vai até o $101^{\circ}$ dia após o pleno florescimento. A fase II tem início logo após a fase de transição, prolongando-se até o $251^{\circ}$ dia após o pleno florescimento. A fase III de amadurecimento do fruto inicia-se no $251^{\circ}$ dia após o pleno florescimento e prolongase até a colheita dos frutos.

Esses resultados diferem daqueles encontrados por Mehouachi et al. (1995), que relataram que a fase I da tangerineira 'Clausellina' tem duração de 42 dias, com o período de transição para a fase II do $42^{\circ}$ até o $52^{\circ}$ dia após a antese. Por sua vez, Bain (1958) relatou que a duração da fase II em variedades precoces é de 60 dias e, nas tardias, pode variar de 150-180 dias, estando este último período de acordo com os valores obtidos na fase II da tangerineira 'Poncã', que apresentou duração de 166 dias, incluindo o período de transição. As diferenças observadas entre os autores, na duração das fases de crescimento dos frutos, provavelmente se devem às características genéticas de cada espécie e variedade, bem como às condições ambientais, a que as plantas estavam expostas.

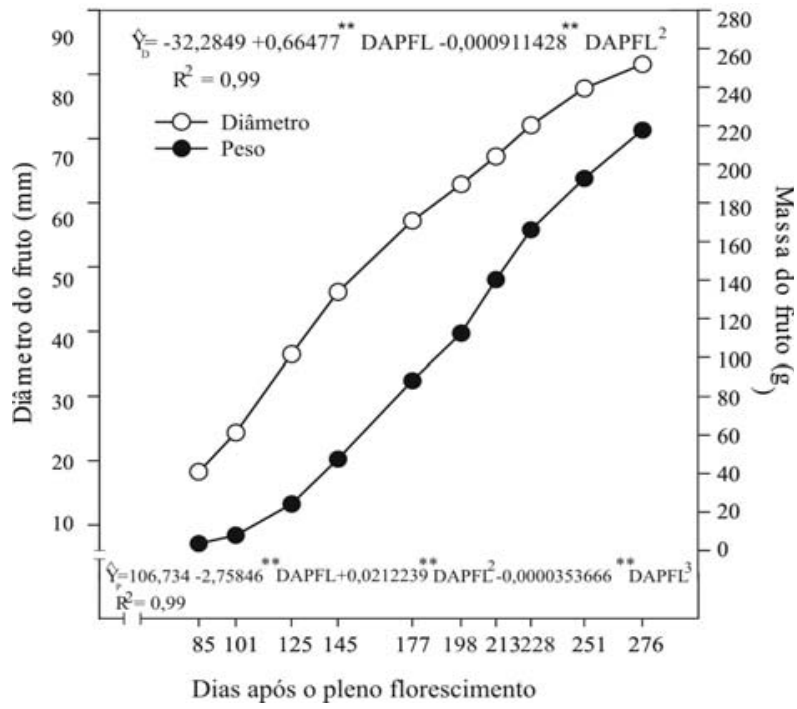

FIGURA 1 - Crescimento de frutos de tangerineiras 'Poncã', do pegamento até o amadurecimento.

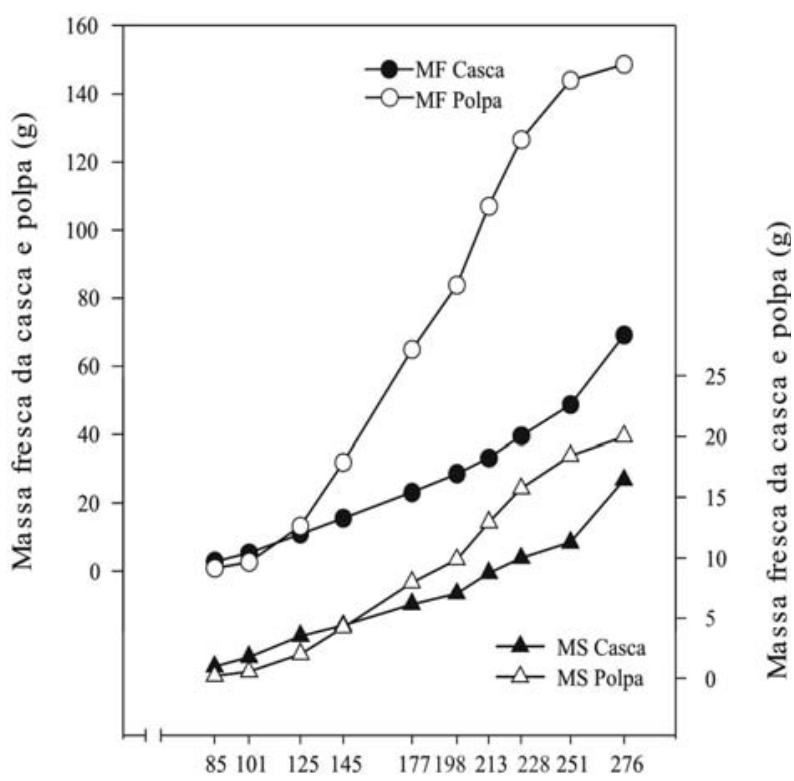

Dias após o pleno florescimento

FIGURA 2 - Crescimento da casca e polpa de frutos de tangerineiras 'Poncã', no período de pós-queda fisiológica até o amadurecimento.

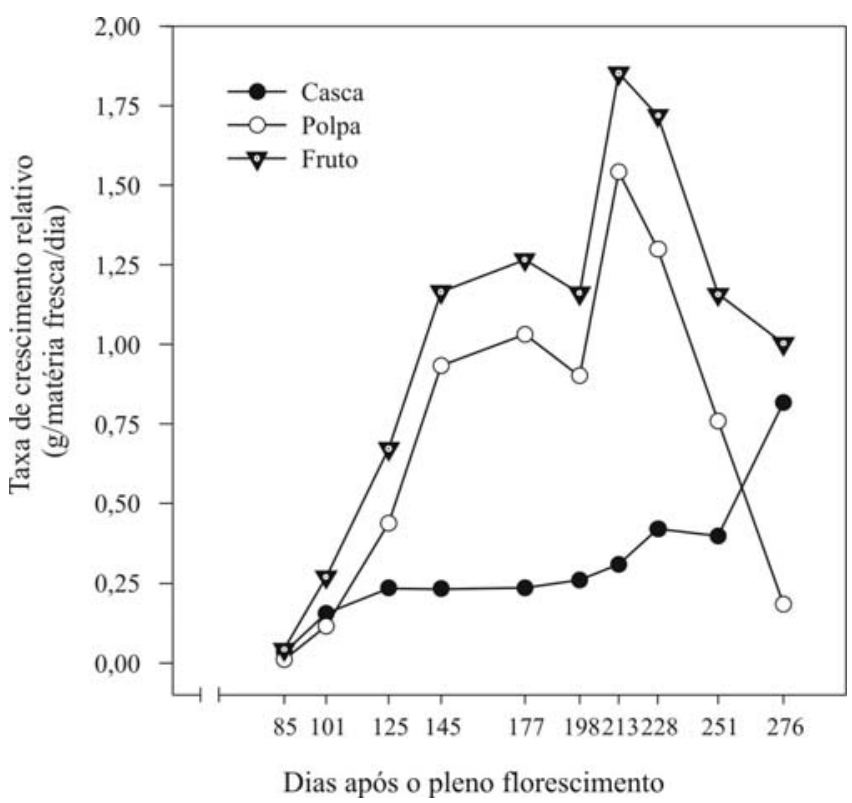

FIGURA 3 - Taxa de crescimento relativo de fruto, casca e polpa, do pegamento até o amadurecimento. 
TABELA 1 - Características químicas e físicas de amostras de solo da área experimental.

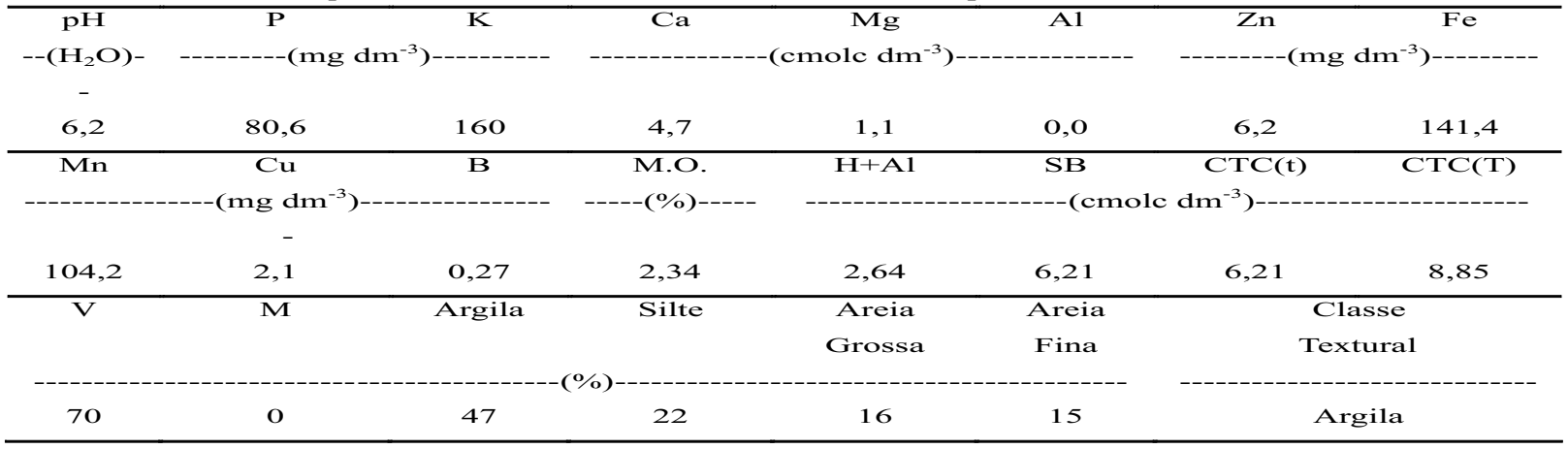

pH em água: $\mathrm{KCl}$ e $\mathrm{CaCl}_{2}(1: 2,5)$.

$\mathrm{P}, \mathrm{K}, \mathrm{Fe}, \mathrm{Zn}, \mathrm{Mn}$ e $\mathrm{Cu}$ : extrator Mehlich 1

$\mathrm{Ca}, \mathrm{Mg}$ e Al: extrator $\mathrm{KCl}-1 \mathrm{~mol} \mathrm{~L}^{-1}$.

B: Extrator água quente.

M.O.: C. Org. x 1,724 (Walkley-Black).

Análise física: Embrapa (1979).

TABELA 2 - Equações utilizadas para estimar a massa fresca do fruto da casca e da polpa de frutos de tangerineira 'Poncã', no período da pós-queda fisiológica até a colheita ${ }^{(1)}$.

\begin{tabular}{|c|c|c|c|c|c|c|}
\hline Época $^{(2)}$ & Massa do fruto & $\mathbf{r}$ & Massa da casca & $\mathbf{r}$ & Massa da polpa & $\mathbf{r}$ \\
\hline --DAPF-- & ---------g/fruto------- & & ---------g/fruto-------- & & ---------g/fruto-------- & \\
\hline 85 & $Y=-7,4521+0,6097 D$ & 0,97 & $\mathrm{Y}=0,5755+0,6197 \mathrm{PF}$ & 0,97 & $Y=-0,5755+0,3803 \mathrm{PF}$ & 0,93 \\
\hline 101 & $Y=-14,389+0,9199 D$ & 0,95 & $\mathrm{Y}=0,8032+0,5653 \mathrm{PF}$ & 0,99 & $\mathrm{Y}=-0,8032+0,4347 \mathrm{PF}$ & 0,99 \\
\hline 125 & $Y=-48,631+1,9965 D$ & 0,98 & $\mathrm{Y}=3,9405+0,2903 \mathrm{PF}$ & 0,89 & $\mathrm{Y}=-3,9405+0,7097 \mathrm{PF}$ & 0,98 \\
\hline 145 & $Y=-85,737+2,8878 D$ & 0,95 & $\mathrm{Y}=3,2501+0,26 \mathrm{PF}$ & 0,95 & $\mathrm{Y}=-3,2501+0,74 \mathrm{PF}$ & 0,99 \\
\hline 177 & $Y=-146,92+4,1071 D$ & 0,94 & $Y=-2,3745+0,2897 \mathrm{PF}$ & 0,92 & $\mathrm{Y}=2,3745+0,7103 \mathrm{PF}$ & 0,99 \\
\hline 228 & $Y=-263,40+5,9571 D$ & 0,93 & $Y=-4,9151+0,2678 P F$ & 0,97 & $\mathrm{Y}=4,9151+0,7322 \mathrm{PF}$ & 0,99 \\
\hline 251 & $Y=-392,02+7,5160 D$ & 0,83 & $\mathrm{Y}=15,269+0,1735 \mathrm{PF}$ & 0,81 & $Y=-15,269+0,8265 P F$ & 0,99 \\
\hline 276 & Colheita & & Colheita & & Colheita & \\
\hline
\end{tabular}

(1)As equações do peso fresco do fruto foram obtidas em função do diâmetro (D), as demais em função dos valores estimados da massa fresca do fruto (PF) (2) Dias após o pleno florescimento (DAPF)

TABELA 3 - Equações utilizadas para estimar a massa seca da casca e polpa de frutos de tangerineiras 'Poncã', do pegamento dos frutos até a colheita ${ }^{(1)}$

\begin{tabular}{|c|c|c|c|c|}
\hline Época $^{(2)}$ & Massa da casca & $\mathbf{r}^{2}$ & Massa da polpa & $\mathbf{r}^{2}$ \\
\hline --DAPFL -- & -------- $\left(\mathrm{g}\right.$ fruto $\left.{ }^{-1}\right)$ & & $------\left(\right.$ g fruto $\left.^{-1}\right)---$ & \\
\hline 85 & $\hat{\mathrm{Y}}=0,2712+0,1913 \mathrm{PF}$ & 0,96 & $\hat{\mathrm{Y}}=-0,0909+0,078 \mathrm{PF}$ & 0,93 \\
\hline 101 & $\hat{Y}=0,4299+0,1692 \mathrm{PF}$ & 0,97 & $\hat{Y}=-0,087+0,081 P F$ & 0,99 \\
\hline 125 & $\hat{\mathrm{Y}}=1,3656+0,0889 \mathrm{PF}$ & 0,84 & $\hat{\mathrm{Y}}=-0,1183+0,0883 \mathrm{PF}$ & 0,98 \\
\hline 145 & $\hat{\mathrm{Y}}=1,3013+0,0648 \mathrm{PF}$ & 0,83 & $\hat{\mathrm{Y}}=0,6624+0,0753 \mathrm{PF}$ & 0,86 \\
\hline 177 & $\hat{\mathrm{Y}}=-0,0722+0,0706 \mathrm{PF}$ & 0,83 & $\hat{\mathrm{Y}}=0,0026+0,0904 \mathrm{PF}$ & 0,88 \\
\hline 198 & $\hat{\mathrm{Y}}=-0,5083+0,067 \mathrm{PF}$ & 0,91 & $\hat{\mathrm{Y}}=0,2669+0,0898 \mathrm{PF}$ & 0,99 \\
\hline 213 & $\hat{\mathrm{Y}}=2,1698+0,0469 \mathrm{PF}$ & 0,90 & $\hat{\mathrm{Y}}=0,135 \quad+0,0931 \mathrm{PF}$ & 0,98 \\
\hline 228 & $\hat{\mathrm{Y}}=0,6106+0,0638 \mathrm{PF}$ & 0,90 & $\hat{\mathrm{Y}}=0,986+0,0888 \mathrm{PF}$ & 0,96 \\
\hline 251 & $\hat{\mathrm{Y}}=4,3449+0,0359 \mathrm{PF}$ & 0,81 & $\hat{\mathrm{Y}}=3,7023+0,0764 \mathrm{PF}$ & 0,70 \\
\hline 276 & Colheita & & Colheita & \\
\hline
\end{tabular}

${ }^{(1)}$ As equações da massa seca da casca e polpa foram obtidas em função dos valores estimados da massa fresca do fruto (PF).

(2) Dias após o pleno florescimento (DAPFL).

Rev. Bras. Frutic., Jaboticabal - SP, v. 30, n. 3, p. 657-661, Setembro 2008 


\section{CONCLUSÕES}

1- O desenvolvimento da tangerina 'Poncã' seguiu uma curva do tipo sigmóide simples, caracterizada por três períodos diferenciados, que são o exponencial (fase I), o linear (fase II) e o amadurecimento (fase III).

2- A fase I estendeu-se da antese até o $85^{\circ}$ dia após o pleno florescimento, com um período de transição para a fase II, que foi até o $101^{\circ}$ dia após o pleno florescimento.

3- A fase II iniciou-se logo após a fase de transição, prolongando-se até o $251^{\circ}$ dia após o pleno florescimento.

4- A fase III de amadurecimento do fruto iniciou-se no $251^{\circ}$ dia após o pleno florescimento e prolongou-se até a colheita dos frutos, a qual foi realizada no $276^{\circ}$ dia após o pleno florescimento.

\section{REFERÊNCIAS}

BAIN, J. M. Morphological anatomical and physiological changes in the developing fruit of the valencia orange (Citrus sinensis (L.) Osbeck). Anstaesse Journal of Botany, Hofgeismar, v.6, p.1-28, 1958.

FONFRIA, M. A.; ORENGA, V. A.; ALCAINA, M. A.; FERRER, M. J.; ROMERO, V. E. Citros: desenvolvimento e tamanho final do fruto. Porto Alegre-RS: 1996. 102p.

GENÚ, P. J. C. Teores de macro e micronutrientes em folhas de porta-enxertos cítricos (Citrus spp) de pés-francos e em folhas de tangerineira 'Poncã' (Citrus reticulata, Blanco) enxertada sobre os mesmos porta-enxertos. 1985. 156 f. Tese (Doutorado em Fitotecnia) - Escola Superior de Agricultura Luiz de Queiroz, Piracicaba, 1985.
GUARDIOLA, J. L.; BARRÉS, M. T.; ALBERT, A.; GARCÍA-LUIS, A. Effects of exogenous growth regulators on fruit development in Citrus unshiu. Annals of Botany, London, v.71, n.1, p.169-176, 1993.

HAYAMA, H.; SHIMADA, T.; ITO, A.; YOSHIOKA, H.; KASHIMURA, Y. Changes in the levels of mRNAs for putative cell wall-related genes during peach fruit development. Scientia Horticulturae, Amsterdan, v.91, n.1, p.239-250, 2001.

MEHOUACHI, J.; SERNA, D.; ZARAGOZA, S.; AGUSTI, M.; TALON, M.; PRIMO-MILLO, E. Defolation increases fruits abscission and reduces carbohydrate levels in developing fruits and woody tissues of Citrus unshiu. Plant Science, Limerick, v.107, n.2, p.189-197, 1995

MILLER, S. A.; SMITH, G. S.; BOLDINGH, H. L.; JOHANSSON, A. Effects of water stress on fruit quality attributes of kiwifruit. Annals of Botany, London, v.81, n.1, p.73-81, 1998.

PIO, R.M.; AZEVEDO, F.A.; DE NEGRI, J.D.; FIGUEIREDO, J.O.; CASTRO, J.L. Características da variedade Fremont quando comparadas com as das tangerinas 'Ponkan' e 'Clementina Nules'. Revista Brasileira de Fruticultura, Jaboticabal, v.28, n.2, p.36$38,2006$.

SALIBE, A. A. Curso de especialização em fruticultura: cultura de citros. Recife, PE: Convênio SUDENE/UFRPe, 1997. 188p.

SPIEGEL-ROY, P.; GOLDSCHMIDT, E. E. 6. Reproductive physiology: flowering and fruiting. In: Biology of citrus. Cambridge: Cambridge University Press, 1996. p.70-125. 